\title{
On My Own
}

Teaching Writing as a Research Librarian Kaeley McMahan, Wake Forest University

\begin{abstract}
For two years, I co-taught the research portion of both introductory and advanced research and writing courses at the Wake Forest University School of Divinity, along with their academic skills instructor. When my co-instructor left the University in Fall 2018, I was asked to continue teaching the introductory course on my own. While I felt confident in teaching about research, I had never taught writing in a formal way. In this presentation summary, I discuss the student learning objectives and course syllabus, as well as ideas for writing-focused course readings, assignments, classroom exercises, and lecture topics. Finally, I explain how changes to the major course project were inspired by ideas shared during a 2019 Atla Annual session.
\end{abstract}

Full course syllabus, assignments, reading list, etc., along with the 2020 conference presentation PowerPoint, can be found at: tinyurl. com/y9y4bt28

\section{OVERVIEW OF CDS512: INTRODUCTION TO RESEARCH AND WRIT- ING}

CDS512: Introduction to Research and Writing is a one-credit elective course taught within the School of Divinity at Wake Forest University. The course consists of eight 90-minute class sessions during the Fall semester. While my experience as a librarian and instructor is weighted towards research topics, I have attempted to maintain even coverage of both research and writing skills across the class sessions, assignments, and readings in the course.

The course learning objectives are for students to be able to:

- Access and select appropriate reference books, scholarly books, and academic journal articles based on research needs.

- Incorporate research into written work and cite resources properly. 
- Think and write critically about research sources.

- Practice effective reading strategies for comprehension and retention.

- Create an outline and craft a strong thesis statement for longer papers.

Because these learning objectives are in pedagogical language, I also include more straight-forward objectives, with specific examples, in the syllabus:

My intention with this course is to introduce you to the variety of resources available to you at the ZSR Library, and equip you with the skills to locate, evaluate, and incorporate them into your work at the School of Divinity. In order to accomplish this, we will:

- learn about the different types of resources used in biblical studies and theological research

- learn how to construct search strategies that can be used in the library catalog and important databases, such as Atla and JSTOR

- learn how to evaluate the resources you find in the catalog and databases, and what resources are best for different types of projects

- learn how to quote or paraphrase the most helpful pieces of information you find for appropriate use in your writing

- learn how to write citations in the Turabian 9 format and the ethical considerations surrounding proper citations

\section{STRATEGIES FOR TEACHING WRITING}

\section{Readings about Writing}

A Manual for Writers of Research Papers, Theses, and Dissertations, 9th ed. (Turabian 2018), is the required citation style guide for the School of Divinity, and it has proved to be a valuable text for the course. Between the research and writing portions of the course, the students are assigned almost the entire first section of the book, as well as several chapters that cover citations and writing style in the second and third sections. As many of the students in the School of Divinity are embarking on their second or third careers, the thorough overview of writing that Turabian outlines frequently helps 
to lessen any writing anxiety they might have brought with them into the program.

The other explicitly writing-focused reading is a chapter from The Seminary Student Writes, "Reading to Write" (Core 2000, 29-46), which gives good, practical advice on dealing with the significant amounts of reading students will engage with during divinity school. Importantly, Core focuses on how reading well can set students up to write well, too.

\section{Writing-oriented Assignments}

Close Reading, Article Analysis, and Peer Review: Students are assigned the article, "Which God is With Us?” (Reid 2010), which has been placed on course reserve, and they must complete an analysis of it based on a close reading guidelines handout. A hard-copy rough draft of a two-page article analysis, comprised of one page of discussion and one page of analysis, is then brought to class. As a group, we discuss the article, and then the students are paired and exchange rough drafts for peer review. After reading each other's drafts, the students share constructive feedback, with explicit instructions that they are not to look for grammar or punctuation mistakes, but rather emphasize their classmate's evaluation or analysis of Reid's argument. The students then have two weeks (including Fall Break) to complete and turn in a final paper.

Writing Center Report: This assignment is designed to make students aware of the student support services that are available to them on campus. They are to meet with one of three services: a tutor at the Writing Center, the academic skills counselor for the School of Divinity, or a counselor or coach at the Learning Assistance Center. Their meeting is not required to be about an assignment for this course, but can cover any academic issue they may be having, such as test or writing anxiety, general study skills, note taking, or paper outlining. After their meeting, the students must write a two-page reflection paper describing their experience and what skills or tips they learned (or didn't learn) from the session. This assignment is given in the first class meeting and the students have until the last day of the course to turn in their reflection. During the last class session, the students share what was helpful about their individual meetings, though I remind them that, because of privacy concerns, they are not required to do so. 
Academic Plan: This assignment contributes to both the reading and writing aspects of the course. Students are required to fill out two sets of calendars. One is a weekly calendar that reflects their "normal" recurring weekly activities: classes, internships, church work, study groups, student organization meetings, sleep, etc. The other calendars are for each month in the semester. These are filled out by consulting their course syllabi and filling in the due dates for tests, papers, projects, and other course activities. The students are then encouraged to include incremental due dates for rough drafts, outlines, or research time so that they can keep their projects on schedule. Along with these calendars, they write a two-page plan that discusses strategies for successfully completing the semester, where problems might occur, and previous academic challenges or successful strategies that may impact their new course of study. As this plan will surely change as the semester progresses, we have verbal check-ins twice during the rest of the course.

Research and Writing Reflection: This assignment also combines both course topics. At the end of the course, the students turn in a two-page reflection on how their approach to library research and/ or academic writing has changed during the course. They can discuss any aspect they would like, but I do provide some prompts they can consider, such as:

- New resource(s) discovered or used.

- A change in anxiety around research/writing.

- A change in planning or organization around the research or writing processes.

- Did reviewing a classmate's writing impact or change your own writing?

- Did the concept of "scholarship as conversation" change how you viewed either the research or writing processes?

\section{Lectures and In-class Exercises}

Class Two - Getting to a Research Topic and Free-writing Exercise: The reading assignment prior to class two is to read the first two chapters of the Turabian text. For the lecture portion of the session, I summarize the process of defining a project that Turabian outlines in chapter two and we discuss what that might look like for their semester projects. Then we move into a free-writing exercise 
that gets them to start thinking about possible research topics. The exercise is based on the idea that you must start writing something, even if it is the wrong thing, so that you can then correct and expand it into what you actually want to say (Elbow 1973, 26). The exercise is composed of these five steps:

1) Write (five minutes): lists, questions, words, names, places, pictures, etc.

2) Underline (two minutes): what was interesting or thoughtprovoking in what you wrote?

3) Write (two minutes): can you come up with a starting topic statement or question?

4) Share (five minutes): pair up and share your question with your partner. Do they have any new questions or ideas you hadn't thought of?

5) Share (5 minutes): share your revised question with the class.

There are several benefits of this exercise. It is a fun, low-stakes way for students to start writing and get some ideas for their topics, which also gives them a strategy that they can use again on their own when they need to. Additionally, they have a record of what they thought about their topic before they did any research. This can help them remember what ideas were theirs and what ideas they gained by reading and research as they incorporate citations into their papers.

Class Seven - Writing Process, Paraphrasing and Footnotes Exercises: The lecture for class seven begins with a discussion of one strategy for the writing process: plan>compose>revise. Using the Close Reading and Article Analysis assignment as an example, I walk through how to read the assignment instructions and create a plan for what is required to complete the assignment. Next, I summarize composition ideas from Core (2000, 20) and Turabian (2018, 76-7), and offer tips on revision, such as reading your paper out loud or having someone unfamiliar with your topic read it for understanding. The lecture portion ends with an overview of how to incorporate quotations and paraphrases into writing. We look at a few examples, and then move into an exercise. I share a paragraph of text and then two examples of how to paraphrase that text, one that is only paraphrase and one that includes a direct quotation as part of the paraphrase. Then the students have the opportunity to practice writing their own paraphrases. The last exercise in this class 
session has them working on a section of footnotes from one of two journal articles to see if they can find the resources listed (we have access to them all, so they should be able to!). The resources in the footnotes are a mixture of books and journal articles, in English and in other languages, and using various abbreviations, so this is a good opportunity for the students to practice the very important skill of reading footnotes.

\section{CHANGES TO THE RESEARCH PROJECT}

Prior to Fall 2019, all of the research projects for any course I taught were an annotated bibliography, consisting of three resources on a topic (reference, scholarly book, scholarly article), with a search strategy, citation, and annotation for each source. After attending a session by Sarah Bogue and Erica Durham at Atla Annual 2019, I was inspired to change this project to utilize a resource chart requiring the collection of ten resources on a topic. The students also had to write a citation for each resource but only had to write a full annotation for one of them. There were several positive reasons for this change, including:

- requires more citation practice;

- gives the students a visual reminder of what to look for in scholarly sources;

- allows students to incorporate other types of resources, such as video lectures, primary sources, digital humanities projects, or podcasts;

- helps students see all of their sources at once and can help them see either overrepresentation or gaps in resource type, authors, or publication dates.

After trying this new approach in Fall 2019, I think there are a few changes I might make to the chart, such as more explicit instructions in the column headers, but on the whole I think it was a good update to the course. 


\section{WORKS CITED}

Bogue, Sarah and Erica Durham. 2019. "Two Research Courses, Two Miles Apart, Two Completely Different Approaches.” Presented at Atla Annual, Vancouver, BC, June 13.

Core, Deborah. 2000. The Seminary Student Writes. St. Louis, MO: Chalice Press.

Elbow, Peter. 1973. Writing without Teachers. New York: Oxford University Press.

Reid, Barbara. 2010. “Which God is with Us?” Interpretation 64, no. 4 (October): 380-9.

Straub, Richard. 1999. "Responding—Really Responding-to Other Students' Writing.” In The Subject is Writing: Essays by Teachers and Students, edited by Wendy Bishop, 136-46. Portsmouth: Boynton/Cook.

Turabian, Kate L. 2018. A Manual for Writers of Research Papers, Theses, and Dissertations. Ninth edition. Chicago: University of Chicago Press. 